\title{
PENGENALAN KULINER TRADISIONAL SEBAGAI DAYA TARIK WISATA BELITUNG
}

\author{
Rosdiana Pakpahan', Yustisia Kristiana² \\ ${ }^{1}$ Universitas Pelita Harapan \\ ${ }^{2}$ Universitas Pelita Harapan
}

Rosdiana.pakpahan@uph.edu, yustisia.kristiana@uph.edu

\begin{abstract}
Abstrak
Perkembangan industri pariwisata dapat memberikan peluang bagi produk-produk wisata termasuk kuliner di Belitung. Tingginya perkembangan industri pariwisata, memberikan peluang yang sangat besar bagi masyarakatnya, untuk ikut berpartisipasi dalam pembangunan wisata kuliner, yang saat ini masih terbatas jumlahnya. Tulisan ini bertujuan untuk menjelaskan makanan tradisional kuliner lokal sebagai daya tarik wisata belitung dan memberikan manfaat kepada masyarakat dalam bentuk tumbuh dan berkembangnya motivasi, minat dan mental berwirausaha, serta adanya peningkatan kemampuan dalam mengembangkan kuliner lokal.
\end{abstract}

\section{Kata Kunci: makanan tradisional, kuliner, daya tarik wisata}

\section{PENDAHULUAN}

Wisata kuliner menjadi suatu alternatif dalam mendukung potensi wisata alam, wisata budaya, wisata sejarah dan wisata bahari. Wisata kuliner ini menjadi bagian dari jenis wisata yang ada, karena tidaklah lengkap kalau wisatawan yang datang tidak mencoba kuliner khas di daerah tersebut. Meskipun wisata kuliner sering dianggap sebagai produk wisata pelengkap, tetapi wisata kuliner potensial untuk dikembangkan karena wisatawan yang datang biasanya tertarik untuk mencoba makanan khas daerah tersebut.

Belitung merupakan salah satu pulau di Indonesia yang terletak di Provinsi Kepulauan Bangka Belitung. Belitung atau Belitong berasal dari bahasa setempat yang diambil dari nama sejenis siput laut, dahulu Belitung dikenal sebagai Biliton. Kabupaten Belitung dalam perkembanggannya menjadi dua kabupaten yaitu kabupaten Belitung yang beribu-kota di Tanjung Pandan dan Kabupaten Belitung Timur yang beribu-kota di Manggar. (Dinas
Kebudayaan dan Pariwisata Kabupaten Belitung, 2017).

Belitung tidak hanya terkenal akan pantainya yang indah, makanan di Belitung memiliki keanekaragaman dan cita rasa yang tinggi. Olahan hasil laut yang melimpah dan rasa yang didominasi oleh rempah-rempah menjadi modal utama kuliner khas Belitung. Percampuran tradisi warga Tionghua di kuliner Belitung sangatlah besar, yang menjadikan kuliner di Belitung sangatlah beragam.

Masih rendahnya motivasi, minat serta mental berwirausaha dikalangan para peserta pelatihan. Para peserta pelatihan belum memahami tentang pentingnya budaya lokal khususnya pada kuliner tradisional, yang menjadi bagian pembangunan wisata kota. Atas dasar alasan tersebut, maka dianggap penting untuk dilaksanakan pengabdian kepada masyarakat yang diharapkan dapat memberikan manfaat dalam bentuk tumbuh dan berkembangnya motivasi, minat dan mental berwirausaha, serta adanya peningkatan kemampuan 
dalam mengembangkan kuliner tradisional, terhadap peserta pelatihan dan diharapkan juga akan menjadi

pendorong untuk tumbuhnya kemauan dan motivasi bagi masyarakat sekitar tempat pengabdian kepada masyarakat, yang juga sebagai tujuan dilaksanakannya pengabdian kepada masyarakat ini.

\section{METODE}

Berdasarkan permasalahan tersebut maka solusi yang dapat ditawarkan adalah:

1. Presentasi dan pemberian informasi mengenai halhal yang berhubungan dengan wisata kuliner dan kuliner tradisional:

- Pengertian wisata kuliner

- Wisata kuliner menurut KBBI 2016 Wisata adalah "bepergian bersama-sama (untuk memperluas pengetahuan, bersenangsenang, bertamasya dan sebagainya.

- Kuliner yaitu sesuatu yang berhubungan dengan masak-memasak.

- Wisata kuliner yaitu wisata yang dilakukan untuk menikmati aneka ragam masakan dari berbagai daerah.

- Menurut Asosiasi Pariwisata Kuliner Internasional (International Culinary Tourism Association/ICTA) wisata kuliner merupakan kegiatan makan dan minum yang unik dilakukan oleh setiap pelancong yang berwisata.

- Kuliner sebagai daya tarik wisata Belitung

- Salah satu nilai pentingnya adalah menumbuh kembangkan potensi makanan asli daerah yang sepertinya sudah mulai tergeser oleh produk-produk asing.

- Untuk itu perlu dibuat sebuah usaha untuk meningkatkan potensi ekonomis ini dengan memberikan sentuhan atau dukungan untuk dapat menarik wisatawan lokal atau asing dalam menikmati kuliner asli daerah.

- Wisata kuliner menjadi suatu alternatif dalam mendukung potensi wisata alam, wisata budaya, wisata sejarah dan wisata bahari. Karena tidaklah lengkap kalau wisatawan yang datang, tidak mencoba kuliner khas di daerah tersebut. Meskipun wisata kuliner sering dianggap sebagai produk wisata pelengkap, tetapi wisata kuliner potensial untuk dikembangkan karena wisatawan yang datang biasanya tertarik untuk mencoba makanan khas daerah tersebut.

- Pengertian makan Bedulang

- makan bedulang dapat diartikan dengan 'makan menggunakan dulang

- makan bedulang adalah prosesi makan bersama dalam satu dulang, terdiri dari empat orang duduk bersila dan saling berhadapan mengitari dulang berisi makanan yang disajikan dan dinikmati dengan tatacara dan etika tertentu

- Dalam kehidupan sehari-hari, makan bedulang berlangsung secara informal dan menjadi sarana komunikasi antar anggota keluarga, dimana pendidikan etika diajarkan secara tidak langsung pada saat makan bersama. Sedangkan dalam upacara adat seperti maras taun, syukuran kelahiran, sunatan, pernikahan atau upacara adat lainnya, makan bedulang merupakan jamuan makan bersama

\section{- Pentingnya tradisi makan Bedulang}

- makan bedulang menggambarkan sistem kebersamaan, toleransim menghargai yang lebih tua dan keberlanjutan hidup bagi generasi penerus. Semua hal diatas akan terlihat ketika mengamati prosesi makan bedulang sejak persiapan, penyahian, adab makan dan adab sesudah makan

$$
\text { Ekonomi, Sosial, dan Budaya }
$$


- filosofi yang terkandung dalam tradisi makan bedulang mengajarkan makna kebersamaan, kerukuran, persatuan, kesetaraan, toleransi, dan rasa syukue

- salah satu ciri khas makan bedulang adalah duduk bersila yaitu duduk dengan cara menyilangkan kedua kaki dibagian betis. Duduk bersila merupakan salah satu posisi duduk yang dicontohkan oleh nabi muhhamad SAW. Duduk bersila merupakan posisi dyduk yang baik, menyehatkan dan sempurna sehingga digunakan dalam makan bedulang

- $\quad$ Kopi Kong Djie Belitung

○ Kong Djie Coffee merupakan warung kopi paling terkenal dan tertua yang ada di Belitung, setiap hari-nya warungkopi ini selalu ramai di kunjungi baik warga lokal maupun wisatawan.

- Kong Djie Coffee sudah dibangun sejak tahun 1943. Pemiliknya bernama Ho Kong Djie,

- Proses pembuatan kopi di Kong Djie menggunakan tiga pot besar. Pot tersebut untuk membuat biang kopi, dengan mencampur satu kilogram bubuk kopi dengan air mendidih. yang kemudian akan diseduh lagi dengan air mendidih dan susu kental manis. Pot tersebut dibiarkan dipanaskan di atas tungku arang yang menyala. Agar rasa kopi-nya melekat.

- Warkop Kong Djie menggunakan bahan baku kopi campuran robusta dari Lampung dan kopi arabika yang dikirim dari pulau Jawa. Warkop Kong Djie mengambil bahan baku dari luar Pulau Belitung dikarenakan Pulau Belitung masih belum memiliki perkebunan kopi. Dengan racikan kopi dan takaran susu kental manis yang pas membuat Kopi Kong Djie sangat diminati

- Perbedaan biji kopi robusta dan arabika
- Biji kopi arabika memiliki rasa yang sedikit asam

- Rasa dari biji kopi arabika tersebut dapat lembut, manis, tajam, dan juga kuat.

- Biji kopi Arabika memiliki aroma seperti buah - buahan

- Biji kopi arabika memiliki tekstur lebih kental dan halus

- Biji kopi arabika hidup pada daerah yang dingin dan sejuk

- Biji kopi robusta memiliki rasa seperti gandum.

- Biji kopi robusta memiliki aroma kacangkacangan.

- Harga biji kopi Arabica lebih mahal bila dibandingkan dengan kopi Robusta.

- Tekstur dari biji kopi robusta ini cenderung kasar

- Biji kopi robusta tumbuh pada dataran rendah

- Perkembangan Kopi Kong Djie Belitung hingga saat ini

- Saat ini ada lebih dari 32 cabang Kong Djie di luar pulau Belitung seperti; Jakarta, Depok, Tanggrang, Bekasi, Bogor, Palembang, Jogja, Bandung, dan Batam. Kunci dari kesuksesan; pelayanan dalam penyajian adalah hal utama yang harus diperhatikan. Soalnya itu pesan orangtua, pembeli itu adalah raja tanpa pandang siapa, Ini hal yang masih dipertahankan sampai sekarang.

- Kue Tradisional Belitung Hok Lo Pan

- Martabak manis ini merupakan makanan khas Bangka Belitung yang diciptakan warga keturunan Tionghoa (Hakka atau Khek). Nama asli makanan ini adalah Hok Lo Pan yang berarti kue orang Hok Lo.

Ekonomi, Sosial, dan Budaya

1056 
- Isi dari martabak manis dulunya hanya berupa gula dan wijen sangrai. Lalu di kembangkan dengan rasa martabak manis yang sesuai dengan selera warga Jakarta, dengan taburan cokelat, kacang dan keju

- $\quad$ Kue Tradisional Belitung

- Kue Rintak, kue pulut panggang dan kue jongkong merupakan tiga dari beberapa jenis kue tradisional yang ada di Belitung. Kue ini tradisional ini sangat dikenal dan rasanya pun sangat-lah nikmat, tetapi di Belitung masih sulit untuk ditemukannya kue-kue tradisional Belitung.

Metode yang digunakan dalam acara ini terbagi ke dalam tiga tahapan yaitu:

\section{Persiapan}

1. Tahap Perencanaan

Hal pertama yang dilakukan pada tahap ini adalah pencarian informasi seputar kuliner khas Belitung lalu dilanjutkan dengan survey ke lokasi untuk mencari tahu kebutuhan daripada target peserta. Selanjutnya, dilakukan konsultasi dengan Dinas Pendidikan Belitung Timur dan melakukan kunjungan ke lokasi untuk memberitahu rencana pelatihan.

2. Tahap Persiapan dan Latihan

Tahap persiapan meliputi pembuatan proposal, pencarian bahan materi, menyiapkan snack box, simulasi, serta sarana dan prasana lainnya untuk menunjang acara.

2. Pelaksanaan program

1. Tahap Pelaksanaan Kegiatan

Peserta diajarkan pentingnya kuliner tradisional sebagai daya tarik wisata Belitung melaui peresentasi dan akan dilanjutkan dengan sesi tanya-jawab. Peserta dapat menanyakan hal-hal yang kurang dimengerti, pengetahuan dan perhatian peserta selama pelatihan dapat diuji. Selama sesi tanya-jawab berlangsung, setiap peserta yang bertanya langsung diberikan souvenir sebagai wujud apresiasi kepada peserta yang bertanya. Setelah acara selesai, panitia langsung membagikan snack box kepada peserta dan langsung makan diruangan.

Berikut merupakan rincian kegiatan,

$\begin{array}{ll}\text { Hari/Tanggal } & \text { : Sabtu, 1 Desember } 2018 \\ \text { Waktu } & : 09.00-12.00 \text { WIB } \\ \text { Tempat } & : \text { SMP Negeri 1 Gantung }\end{array}$

3. Evaluasi

1. Tahap Evaluasi

Evaluasi yang dilakukan berupa kuesioner yang berisikan sejumlah pertanyaan sehubungan dengan pelaksanaan kegiatan. Kuesioner ini diisi oleh semua peserta. Berikut adalah kuesioner yang akan disebarkan di akhir acara:

FORM EVALUASI

PENGENALAN KULINER TRADISIONAL SEBAGAI DAYA TARIK WISATA BELITUNG

Nama :

Tanggal:

Petunjuk Pengisian:

Jawablah pertanyaan ini sesuai dengan pendapat anda mengenai Pengabdian Kepada Masyarakat ini dengan memberi tanda centang $(\checkmark)$ di kolom Ya atau Tidak.

\begin{tabular}{|l|l|l|l|}
\hline No & Deskripsi & Ya & Tidak \\
\hline 1 & Apakah Anda pernah & & \\
& $\begin{array}{l}\text { mengikuti pelatihan } \\
\text { pengenalan kuliner }\end{array}$ & & \\
& $\begin{array}{l}\text { tradisional } \\
\text { sebagai daya tarik }\end{array}$ & & \\
\hline
\end{tabular}

Ekonomi, Sosial, dan Budaya

1057 


\begin{tabular}{|c|}
\hline $\begin{array}{ll}\begin{array}{l}\text { wisata } \\
\text { sebelumnya? }\end{array} & \text { Belitung } \\
\end{array}$ \\
\hline $\begin{array}{lr}\text { Apakah melestarikan } \\
\text { kuliner tradisional } \\
\text { penting di Belitung? }\end{array}$ \\
\hline $\begin{array}{l}\text { Apakah Anda pernah } \\
\text { mengikuti pelatihan } \\
\text { pengenalan kuliner } \\
\text { tradisional } \\
\text { sebagai daya tarik } \\
\text { wisata Belitung } \\
\text { sebelumnya? }\end{array}$ \\
\hline $\begin{array}{l}\text { Apakah materi yang } \\
\text { disampaikan dalam } \\
\text { pengenalan kuliner } \\
\text { tradisional } \\
\text { sebagai daya tarik } \\
\text { wisata Belitung ini } \\
\text { dapat dipahami dengan } \\
\text { mudah oleh peserta? }\end{array}$ \\
\hline $\begin{array}{l}\text { Apakah setelah } \\
\text { mengikuti pelatihan ini, } \\
\text { anda memahami kuliner } \\
\text { tradisional Belitung? }\end{array}$ \\
\hline $\begin{array}{l}\text { Apakah dengan adanya } \\
\text { pengenalan kuliner } \\
\text { tradisional dapat } \\
\text { meningkatkan daya tarik } \\
\text { wisata di Belitung? }\end{array}$ \\
\hline $\begin{array}{l}\text { Apakah infrastruktur } \\
\text { menyampaikan materi } \\
\text { kuliner tradisional } \\
\text { Belitung dengan jelas? }\end{array}$ \\
\hline $\begin{array}{lr}\text { Apakah } & \text { infrastruktur } \\
\text { menguasai } & \text { materi } \\
\text { kuliner } & \text { tradisional } \\
\text { Belitung? } & \\
\end{array}$ \\
\hline $\begin{array}{lr}\text { Apakah } & \text { pengenalan } \\
\text { kuliner } & \text { tradisional } \\
\text { sebagai daya tarik } \\
\text { wisata ratang } \\
\text { sebaiknya dilakukan } \\
\text { secara berkala? }\end{array}$ \\
\hline
\end{tabular}

Saran:

Perbaikan untuk kegiatan Pengabdian Kepada Masyarakat Program Studi Usaha Perjalanan Wisata UPH:

\section{HASIL DAN PEMBAHASAN \\ Pelaksanaan}

Pelaksanaan kegiatan pengabdian kepada masyarakat di Belitung dihadiri oleh siswa dan siswi sekolah SMP Negeri 1 Gantung sejumlah 22 murid. Kegiatan pengabdian kepada masyarakat ini diawali dengan memberikan materi berupa presentasi tentang pengertian wisata kuliner dan kuliner tradisional yang ada di Belitung dan menyampaikan pengetahuan tentang pengembangan wisata kuliner kepada siswa dan siswi sekolah SMP Negeri 1 Gantung.

Adapun materi penyuluhan yang disampaikan yaitu tentang "Pengenalan Kuliner Tradisional Sebagai Daya Tarik Wisata Belitung”. Materi lebih ditekankan pada potensi yang dimiliki oleh Belitung yaitu wisata kuliner.

Pengertian mengenai wisata kuliner dipaparkan terlebih dahulu dalam penyuluhan tersebut agar siswa dan siswi SMP Negeri 1 Gantung lebih mengenal, mengerti dan memahami mengenai wisata kuliner itu

Ekonomi, Sosial, dan Budaya 
sendiri dan kemudian dilanjutkan tentang pentingnya tradisi makan Bedulang dan nilainilai luhur dan makna filosofis makan bedulang.

Pada pengenalan tersebut juga diuraikan mengenai pengembangan makanan khas tradisional Belitung salah satu contohnya yaitu kue Hok Lo Pan. Seni kuliner Belitung sebagai salah satu aspek kebudayaan Belitung diadaptasi sehingga menjadi wisata kuliner. Adaptasi tersebut adri segi bentuk, tujuan dan makna yang melipuiti adaptasi bahan makanan, rasa, pengolahan, penyajian dan cara makan. Seni kuliner Belitung sebagai penunjang pariwisata berdampak budaya, sosial, rasa bangga serta pemenuhan kebutuhan harga diri. Adapun contoh model wisata kuliner yaitu; bisnis perorangan, bisnis organisasi/hotel.

\section{Hasil Kegiatan}

Evalausi dilakukan untuk mengetahui tercapai tidaknya tujuan dan manfaat dari kegiatan PKM ini. Selain itu, untuk mengukur sejauh mana kegiatan ini dilaksanakan dan mendapatkan umpan balik peserta dalam dalam rangka mengembangkan wisata kuliner Belitung diwaktu mendatang.

Evaluasi yang dilakukan berupa angket yang berisikan sejumlah pertanyaan sehubungan dengan pelaksanaan kegiatan. Angket ini diisi oleh semua peserta yang berjumlah 22 orang. Adapun hasil dari evaluasi ini didapat hasil bahwa semua peserta yaitu siswa dan siswi SMPN 1 Gantung ini belum pernah mengikuti pelatihan pengenalan kuliner tradisional sebagai daya tarik wisata Belitung. Berdasarkan hasil dari evaluasi yang didapat bahwa seluru peserta siswa dan siswi SMP Negeri 1 Gantung memahami materi yang disampaikan dengan baik. Para siswa dan siswi SMPN 1 Gantung memiliki keinginan yang kuat untuk mempertahankan dan mengembangkan kuliner tradisional Belitung sebagai daya tarik wisata Belitung.

\section{KESIMPULAN}

Kesimpulan berisi rangkuman hasil kegiatan pengabdian kepada masyarakat dan implikasi dari kegiatan yang dilaksanakan.

Belitung kaya akan tradisi dan rasa kuliner, yang tidak dapat di cari di daerah manapun. Setiap warga Belitung haruslah bangga dan tetap mempertahankan keaslian kulinernya.

- Contoh nyata yang bisa di tiru adalah warung kopi Kong Djie; Kong Djie menjadi salah satu daya tarik bagi wisatawan untuk berkunjung ke Belitung, karena rasa dan pelayananya yang melegenda banyak wisatawan yang ingin mencobanya.

- Tidak sampai disitu saja, Kong Djie juga membawa nama Belitung ke daerah-dearah lain yang ada di Indonesia, dengan cara membuka cabang di luar pulau Belitung. Hal tersebut membuka jalan bagi kuliner-kuliner lain yang ada di Belitung agar bisa di kembangkan untuk mengikuti jaman akan tetapi tetap di jaga keaslian rasanya.

- Belitung menjadi hal utama yang di utamakan oleh pemerintah di bidang Pariwisata, sebagai generasi muda Belitung, masa depan dari belitung ada di tangan anak-anak muda. Tidak hanya objek wisata saja, tetapi Kuliner yang ada di Belitung merupakan warisan yang harus di jaga dan terus di kembangkan tanpa mengubah yang sebenarnya.

\section{UCAPAN TERIMAKASIH}

Ucapan terima kasih disampaikan kepada LPPM Unversitas Pelita Harapan yang telah memberikan kesempatan untuk melakukan PKM di Belitung dengan memberikan nomor Pengabdian kepada Masyarakat di Belitung. Selain itu, penulis juga ingin menyampiakan terima kasih kepada Ibu Dr. Diena M. Lemy, sebagai Dekan Fakultas 
Pariwisata Univeristas Pelita Harapan yang telah memberikan ijin dan kesempatan untuk dapat melakukan PKM tersebut. Tidak sampai disitu saja, penjulis ingin menyampaikan terima kasih kepada semua pihak yang telah membantu yang tidak bisa disebutkan namanya satu persatu dengan baik.

\section{REFERENSI}

Dinas Kebudayaan dan Pariwisata Kabupaten Belitung (2017). Data Kepariwisataan Kabupaten Belitung.
Dinas Kebudayaan dan Pariwisata Kabupaten Belitung (2018). Data Kunjungan Wisnu dan Wisman Kabupaten Belitung.

Dinas Kebudayaan dan Pariwisata Kabupaten Belitung (2018). Makan Bedulang Warisan Budaya Urang Belitong.

Dinas Pendidikan Belitung. Kabupaten Belitung Timur. Kota Manggar (2018).

Kamus Besar Bahasa Indonesia (2018). Pengertian Wisata Kuliner. Hompage On-line.

Diakses dari https://kbbi.kemdikbud.go.id/entri/wisata\%20 kuliner 